\title{
Relato de Aplicação de Uma Avaliação UX Para Aplicativo de Mobilidade Urbana sob a Perspectiva de Idosos
}

\author{
Laura Quevedo Jurgina1, Dauan Ghisleni Zolinger'1, Darlei Matheus Schmegel',

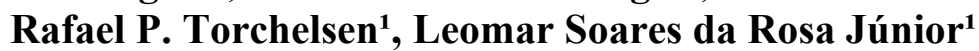 \\ ${ }^{1}$ Universidade Federal de Pelotas (UFPel) - Pelotas, RS - Brasil \\ \{lqjurgina, dgzolinger, dmschemegel, Rafael.torchelsen, leomarjr\}@inf.ufpe \\ 1. edu.br
}

\begin{abstract}
Resumo. $O$ avanço da tecnologia invade o cotidiano das famílias e o emprego do computador em tarefas diárias é cada vez mais comum. As aplicações móveis atingem um público amplo, de faixa etária e nível de instrução diversificados. A inclusão de idosos neste processo implica no emprego de atividades de letramento digital a partir da oferta de plataformas intuitivas e que dialoguem com linguagem simplificada para que as atividades possam ser compreendidas por públicos com maiores dificuldades de utilização. Este trabalho foi realizado pelo grupo PET-COMPUTAÇÃO UFPEL e busca identificar as dificuldades encontradas por idosos na interação com uma aplicação comum no cotidiano, o aplicativo estudado, que traz informações necessárias para a utilização do transporte público. Os obstáculos encontrados no processo de utilização foram investigados a partir de uma avaliação UX, com tarefas intuitivas e chaves para o sucesso no resultado esperado pelo usuário. Dentro deste escopo, o presente trabalho identifica aspectos que fazem barreiras à acessibilidade de interação com um serviço comum no dia-a-dia da cidade.
\end{abstract}

\section{Introdução}

A crescente utilização de smartphones no cotidiano, naturalmente, provoca o emprego da tecnologia nas tarefas que compõem a rotina de uma pessoa. A comunicação acontece, em grande parte, por aplicativos móveis, de maneira rápida e simples, impactando na inclusão de todas as faixas etárias digitalmente (Chen e Fan 2012).

Novos aplicativos surgem todos os dias e exploram diversos temas e necessidades, desde os que trazem mapas, até os de controle de ciclo menstrual. A antiga agenda de papel cada vez perde mais seu espaço para os aparelhos inteligentes. Aqueles que ainda são conhecidos são pesquisados pelo tema que tratam por quem deseja empregar tal funcionalidade em busca da otimização da organização do calendário de tarefas diários (Väätäjä et. al. 2009).

Sendo assim, surgiram aplicativos para auxiliar em uma demanda conhecida por todas as cidades: o transporte público. Estes aplicativos possuem a missão de informar itinerários, horários e rotas otimizadas, para tal, utilizam de mapas no auxílio (Kronbauer et. al. 2014). A proposta da utilização é interessante e de utilidade para o público usuário do transporte, todavia nem todas as funcionalidades são de uso simples para quem utiliza a aplicação.

Falar em transporte público envolve um grupo de usuários extremamente plural. 
É um público de todas faixas etárias e nível de instrução, o que pode gerar múltiplas experiências de usuário ao aplicativo. Este trabalho buscou uma avaliação com um público alvo específico: os idosos (Furtado et. al. 2018).

Neste contexto de avanço tecnológico, onde a atualização dos sistemas empregados no cotidiano chega a todo instante aos dispositivos inteligentes da população, é preciso que a academia se preocupe em auxiliar a todos os públicos a lidar com tais mudanças. Assim é assegurado que os benefícios da computação sejam utilizados por todos. Juntamente a esse dever social, é importante que os grupos de PET (Programa de Educação Tutorial) das universidades se envolvam com atividades de extensão.

Juntamente ao dever dos estudantes de computação, em preocupar-se com públicos que estejam às margens da integração digital, existe a importância da pesquisa cientifica dentro dos grupos PET. Assim, o Grupo PET-Computação da Universidade Federal de Pelotas realizou o estudo acerca de Interação humano-computador com o objetivo de recomendar processos que simplifiquem a utilização de aplicativos por parte da parcela idosa.

\section{Trabalhos correlatos}

Apesar de não existirem trabalhos iguais na literatura, iniciativas semelhantes podem ser observadas com outros objetos de estudo. Como uma avaliação da interface de um jogo mobile educativo voltado para a terceira idade (Mol e Ishitani 2010), demonstra que aplicativos para dispositivos móveis podem ser utilizados efetivamente por esse grupo. Para tal, deve-se levar em consideração no seu desenvolvimento métricas de usabilidade já recomendadas para desktops e notebooks, assim como as experiências anteriores do público-alvo.

Outro trabalho analisa a usabilidade de um aplicativo móvel para treino de memória em idosos (Marchi at al. 2014) e identifica que uma experiência tecnológica prévia e um grau de escolaridade maior facilitam a interação. Também acentua que, devido ao tamanho reduzido da interface, a escolha de cores e contrastes contribuem para a legibilidade e devem receber maior atenção na sua construção.

Já outra pesquisa analisou o comportamento de compra da terceira idade em um site de ecommerce (Almeida e Ferreira 2011) e também defende um olhar mais atento durante o desenvolvimento de produtos para esses usuários. Além de destacar a importância de pequenos ajustes de textos, funcionalidades e testes constantes de usabilidade para mitigação de erros e eventuais melhorias.

Grande parte dos trabalhos observados apontam que as dificuldades encontradas na usabilidade de aplicativos e sites por idosos decorrem da construção de suas interfaces. Não só isso, o desenvolvimento de aplicações inadequadas que não levam em conta as limitações físicas e cognitivas decorrentes do envelhecimento desestimula a adoção e uso de novas tecnologias por esses usuários (Zajicek 2006).

\section{Metodologia}

Este trabalho faz uma avaliação de experiência de usuário com idosos em tecnologia móvel. O aplicativo escolhido está presente em 20 cidades no Brasil e traz dados que buscam informar e auxiliar o usuário do transporte público. Para tal, ele traz opções de 
rota, informações sobre as linhas disponíveis no município e também informes para cada ponto de embarque, comunicando as linhas próximas e previsão de chegada da linha desejada. O aplicativo também permite chamadas de emergência, para comunicar problemas no coletivo e outras configurações como a exibição de informações sobre os ônibus que possuem acessibilidade.

A aplicação do teste de usabilidade deste trabalho busca identificar problemas encontrados por idosos na manipulação deste software. O planejamento de aplicações para o cotidiano, atualmente, deve levar em consideração o público que irá utilizar as aplicações. Neste caso, as limitações encontradas por idosos no fluxo de navegação em dispositivos móveis devem ser exploradas para que soluções direcionadas à inclusão deste grupo sejam discutidas.

Para a avaliação UX da aplicação foi exercido o método de maneira qualitativo, pois o processo do teste de usabilidade precisava ser observado durante a realização das tarefas propostas. A partir da análise do fluxo de trabalho realizado pelo usuário é possível gerar um feedback real (Barbosa e Silva 2010). O emprego deste método de avaliação implica na definição de métricas para observação de modo a verificar se o objetivo da aplicação foi alcançado. Para tal, as métricas escolhidas foram: taxa de sucesso na tarefa, sucesso percebido - levando em consideração o tempo total para a execução da ação solicitada - e a taxa de erro (Pavliscak 2019)

As métricas descritas acima levam em consideração a execução durante a lista de tarefas solicitadas. Todavia, para que fosse alcançado um resultado com contexto e conexão após a execução das tarefas sob avaliação do observador, o usuário foi submetido a um questionário onde demonstra as suas percepções pessoais.

Sendo assim, o fluxo da avaliação aconteceu da seguinte maneira: i) apresentamos o objeto de estudo (aplicativo de transporte coletivo); ii) solicitamos a realização das tarefas desejadas, concomitantemente executamos a observação para identificar o curso de navegação; iii) aplicamos o questionário para coletar as percepções pessoais do usuário.

O público participante da avaliação foi composto por 30 pessoas, todas com idade igual ou maior a 60 anos. A coleta de dados foi realizada em um período de 7 dias com a abordagem de pessoas que estavam no ponto de ônibus. O Aparelho móvel utilizado por todos foi o mesmo com o sistema operacional Android, 50\% tinha entre 60 e $65,20 \%$ entre 66 a 70, 20\% entre 71 e 75 e $10 \%$ tinha mais de 75 anos.

Antes de realizar a avaliação também questionamos os usuários sobre como enxergavam a sua desenvoltura com smartphones, a seguinte pergunta foi realizada "Como você classifica sua relação com a tecnologia móvel?", e o resultado pode ser observado na Figura 2. Tal questionamento é importante para sabermos como o usuário qualifica sua relação com o uso de aplicações móveis. Os resultados seguem na Figura 1 . 


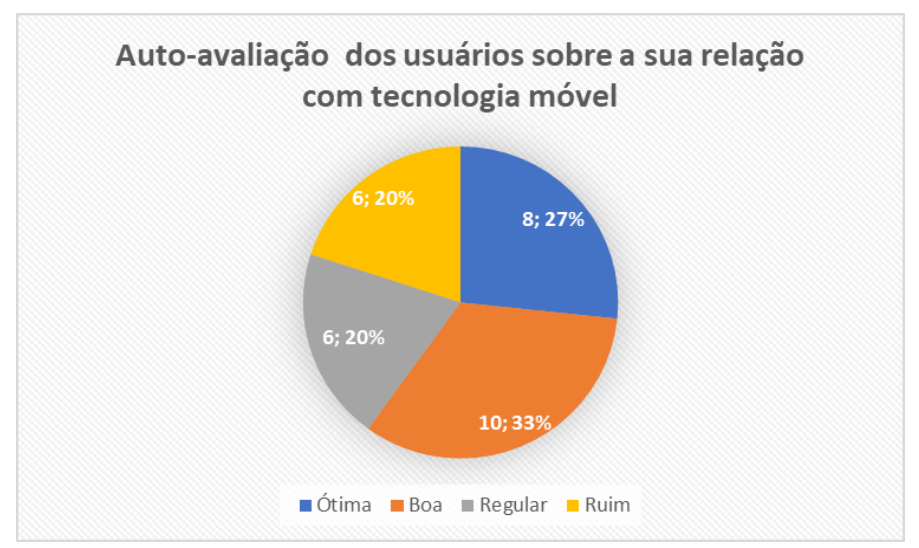

Figura 1. Auto-avaliação dos usuários sobre a sua relação com tecnologia móvel.

\subsection{A Primeira Tarefa}

A primeira tarefa solicitou que os usuários buscassem uma rota de sua preferência no aplicativo. Nesta ação foi observado o tempo de execução para a tarefa assim como o fluxo de trabalho e os erros de navegação.

A tela inicial do aplicativo induz à procura de um itinerário, porém a tarefa inclui outros passos após a pesquisa. Durante esse fluxo de utilização observamos se houveram dificuldades em compreender as opções ofertadas pela aplicação e se a navegação subsequente aos passos escolhidos foi realizada com sucesso.

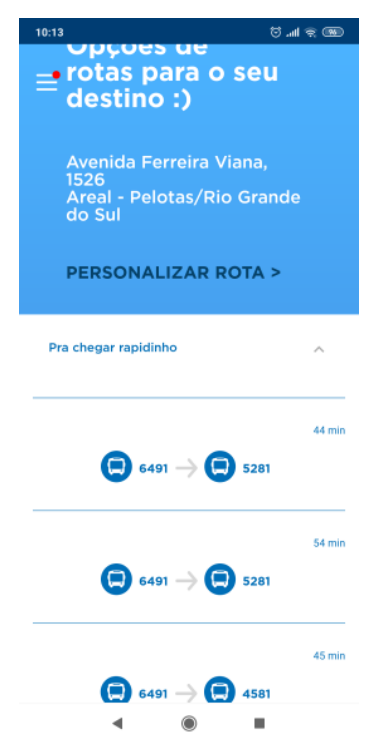

Figura 2. Tela do Aplicativo sugerindo linhas para itinerário.

Ao escolher um destino a aplicação sugere várias rotas possíveis. Neste ponto os usuários tiveram sucesso ao inserir os dados desejados no campo de pesquisa. Na figura 2 podemos visualizar as opções ofertadas para chegar até o shopping da cidade.

A aplicação sugere rotas variadas e com tempos diferentes, o que a princípio causa confusão ao usuário. Neste momento o avaliador observa, além da usabilidade, o engajamento do usuário. Observa-se que alguns tentam analisar a diferença das 
alternativas de modo a compreender as desigualdades entre elas. Alguns mais engajados - após uma breve leitura - acessam alguma das possibilidades, enquanto uma minoria fica bloqueada nesta tela.

Os que avançaram com a escolha de alguma opção o aplicativo dá instruções para começo do itinerário, juntamente ao texto ele também ilustra no mapa, como podese observar na Figura 4. As instruções apresentadas nesta tela são semelhantes às de outros aplicativos de mapas para smartphones, o que traz conforto e fácil compreensão ao usuário, uma vez que essas informações não são novidade para a maior parte dos entrevistados.

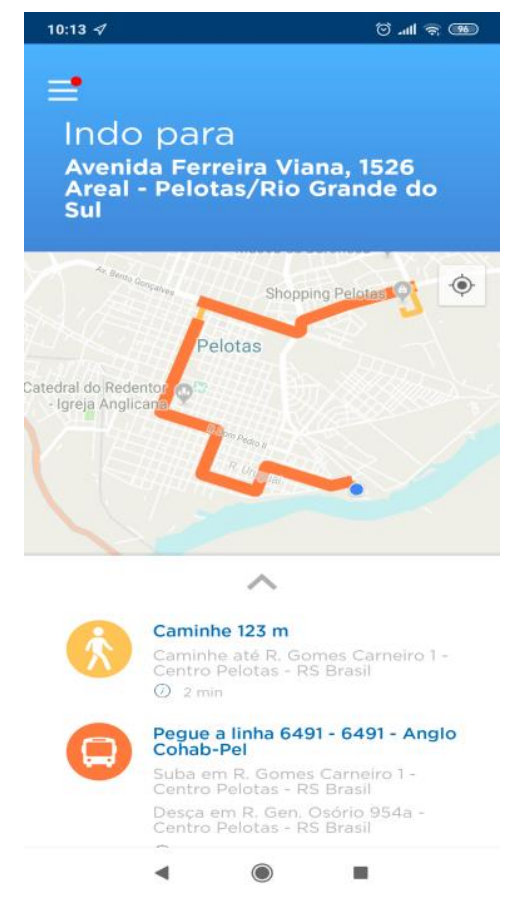

Figura 4. Tela do Aplicativo ilustrando o itinerário.

Mesmo com as semelhanças de outros aplicativos alguns usuários sentiram-se confusos ao encontrar o ponto de ônibus indicado para aquela rota, pois não compreendiam a rota que deveriam realizar caminhando. Na Figura 5, podemos visualizar o tempo utilizado para realização desta tarefa.

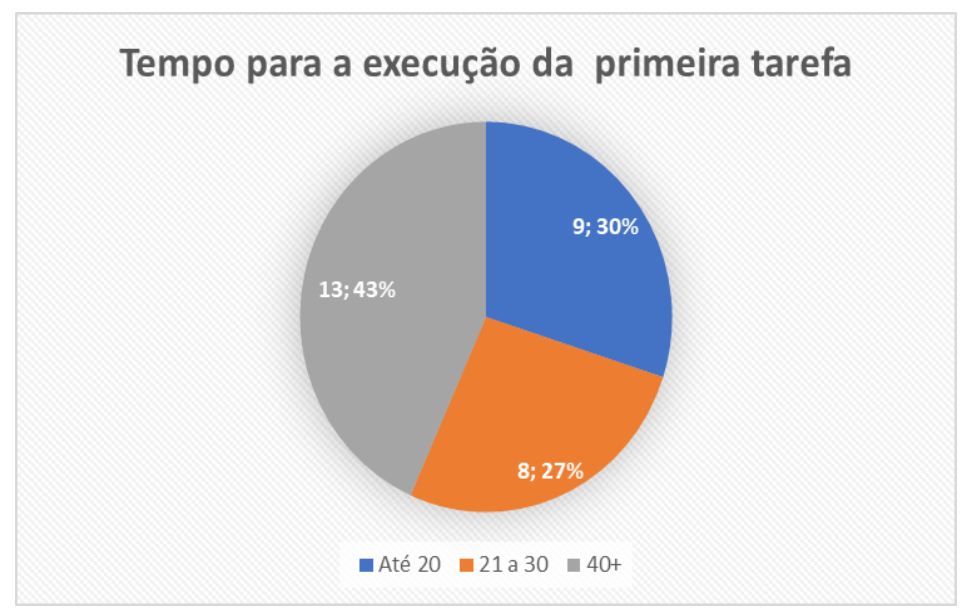

Figura 5. Tempo utilizado para realização da primeira tarefa (em segundos). 


\subsection{A Segunda Tarefa}

A segunda tarefa convidou o idoso a buscar por uma linha de ônibus específica. Nesta ação - diferente da anterior - o usuário precisa utilizar os menus laterais. Assim que o usuário localiza a opção para buscar a linha ele deve selecioná-la e então selecionar qual deseja saber informações. Então as possíveis linhas são sugeridas pela aplicação; algumas linhas já extintas são mencionadas, o que causou uma pequena confusão para o idoso, porém nenhum entrevistado acessou essas opções.

Ao selecionar uma linha o aplicativo apresenta, no mapa, a sua rota e a localização dos pontos onde há embarque e desembarque de passageiros. Isto é ilustrado na Figura 6.

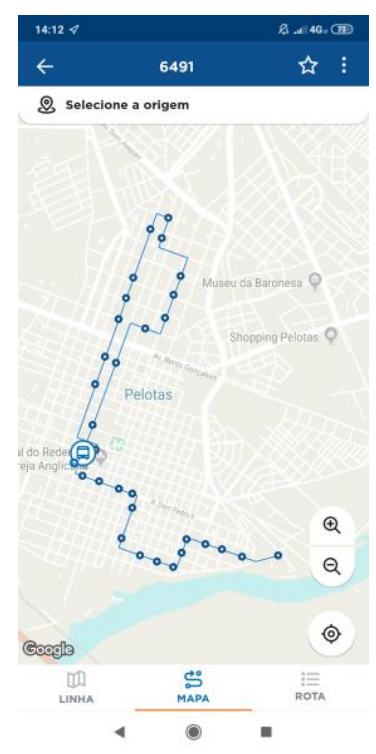

Figura 6. Apresentação da rota de uma linha específica no aplicativo

Para esta tarefa foi observado o tempo para execução de todos os passos para a busca de uma linha específica. A Figura 7 apresenta esta informação. Durante a realização desta tarefa foi observado mais facilidade na navegação das opções apresentadas pelo aplicativo. $\mathrm{O}$ menu era direto e sem caminhos secundários que induzissem ao erro ou confusão entre as alternativas.

\section{Tempo utilizado pelos usuários para a execução da tarefa 2}

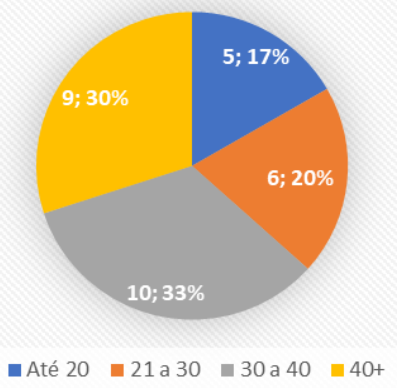

Figura 7: Tempo utilizado para a execução da tarela 2 (em segundos). 


\subsection{A Terceira Tarefa}

O objetivo desta tarefa é testar se o usuário reconhece menus, ícones e identifica tendências de utilização, possibilitando assim identificar onde ocorre a confusão ou a quebra do fluxo de navegação para que então as soluções possam ser alcançadas. A terceira tarefa propõe uma ação onde a usabilidade necessita de engajamento e conversão de informações para seu sucesso. Para tal foram solicitadas duas informações que não possuem chamadas diretas no menu.

A primeira requisitava que o usuário obtivesse a informação das linhas que estavam chegando naquele ponto de ônibus e qual era o coletivo mais próximo. Para executar este pedido o idoso precisava reconhecer, no mapa, o ícone que ilustra um ponto de ônibus, com apresentado na Figura 8, e ter a iniciativa de pressioná-lo para então receber as informações que lhe foram pedidas, que podem ser visualizadas na Figura 9.

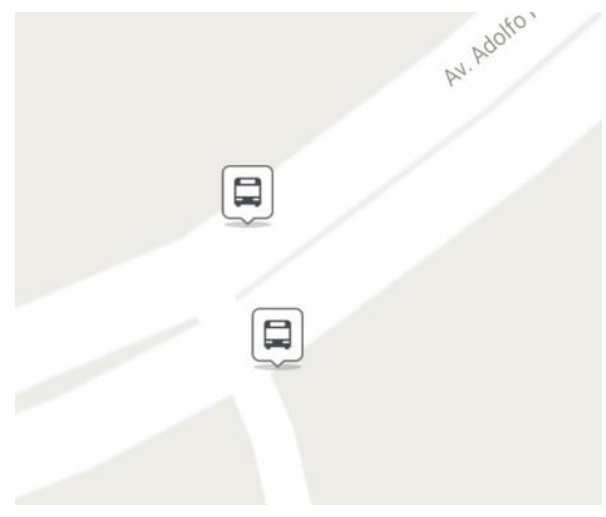

Figura 8: Í́cone que representa o ponto de ônibus.

Para a segunda parte da tarefa o usuário deveria configurar o aplicativo para informar apenas os coletivos adaptados e acessíveis para o embarque de cadeirantes. Para a execução desta ação era necessário que o usuário encontrasse no menu lateral a opção de configuração e a seleciona-se, após o aplicativo já apresenta a alternativa para informar apenas sobre veículos acessíveis, o que pode ser visualizado na Figura 11. Observamos a taxa de sucesso para realização das duas etapas da terceira tarefa. Os resultados são apresentados na Figura 12.

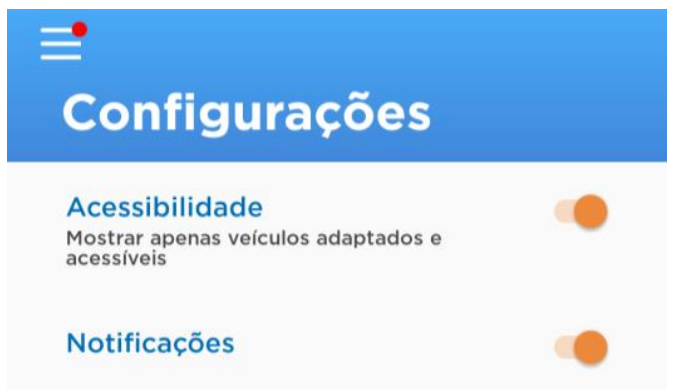

Figura 9. A seleção de informação apenas de veículos adaptados. 


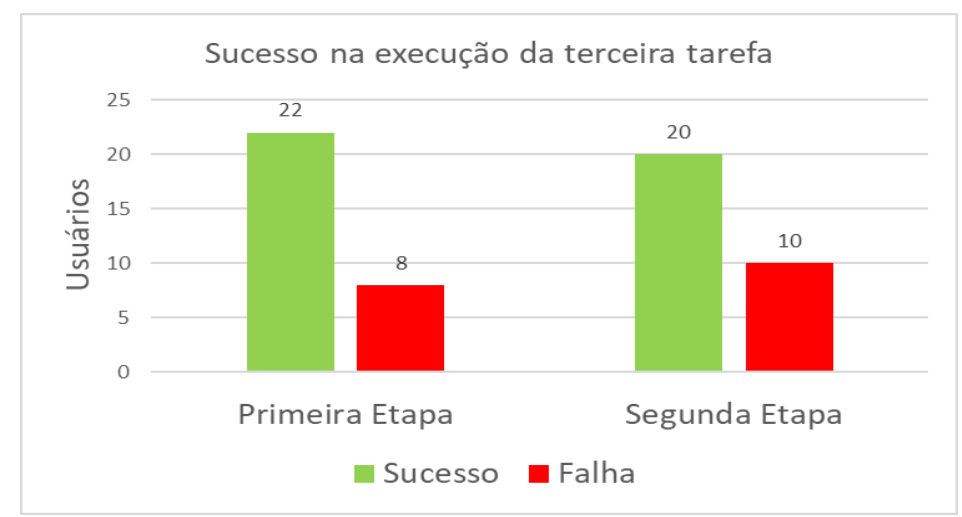

Figura 10. Sucesso na execução da terceira tarefa

\subsection{Avaliação}

Após a utilização da aplicação, os usuários foram convidados a responder um breve questionário sobre a sua experiência. $\mathrm{O}$ questionário buscou compreender o sentimento do idoso após o teste. Na primeira pergunta o usuário foi questionado sobre a tarefa em que mais encontrou dificuldade. Os resultados desta pergunta ajudam na comparação com a observação do avaliador durante a experiência com o aplicativo.

A pergunta realizada foi: "Em qual tarefa você teve mais dificuldade?", e os resultados são apresentados na Figura 11.

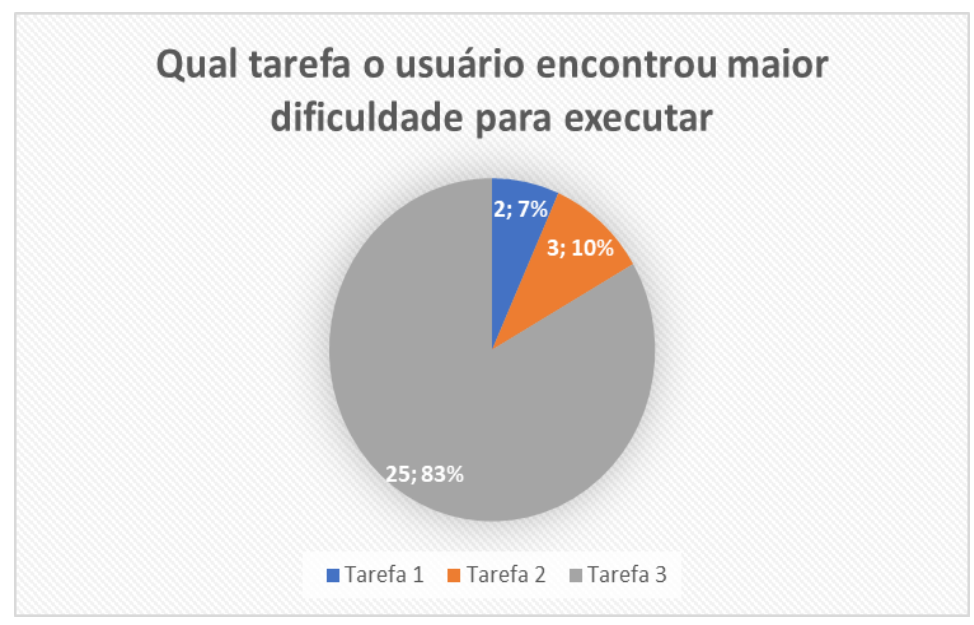

Figura 11. O usuário elege a tarefa mais difícil de executar.

Na segunda pergunta o usuário foi questionado sobre a usabilidade do aplicativo. A pergunta realizada foi: "Você considera adequado os menus e ícones utilizados no aplicativo?". A respostas podem ser visualizadas na Figura 12. 


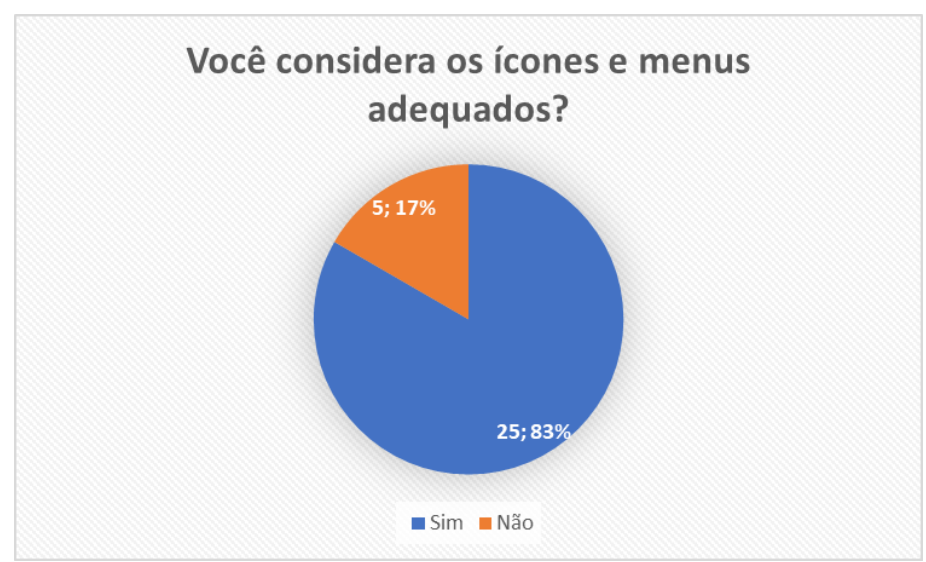

\section{Figura 12. Consideração do usuário sobre os menus e ícones empregados no aplicativo.}

A última pergunta traz uma reflexão do usuário, sobre sua experiência completa, levando em consideração as dificuldades encontradas por ele. $\mathrm{O}$ questionamento realizado foi: "Você considera esse aplicativo acessível para idosos?".83 \% dos idosos responderam que sim, e apenas $17 \%$ respondeu negativamente.

\section{Conclusões}

A partir da observação durante a prática e os resultados encontrados no questionário realizado após o teste foram identificados alguns padrões que possibilitam reconhecer algumas barreiras que impossibilitam o idoso de chegar ao sucesso da sua experiência.

As tarefas onde fora necessário reconhecer ícones, para dar seguimento à ação, não obtiveram taxas de falhas consideráveis, demonstrando, assim, que a navegação intuitiva resulta em mais facilidade para o idoso. Ícones que remetam ao objeto real possuem seleção espontânea, trazendo sensação de segurança para o usuário.

O idoso possui medo de utilizar aplicações, pois acredita que falhas possam remeter a um possível dano na configuração do dispositivo, essa é a razão de encontrarem mais dificuldade na tarefa em que uma configuração foi solicitada. Ao realizarem a terceira tarefa os usuários demonstraram aos observadores que a manipulação de uma aplicação desconhecida os deixa desconfortável pois possuem receio de realizar erros no fluxo de interação.

A primeira tarefa demonstra que a maior parte dos usuários precisaram de um tempo elevado para realização da ação completa. O reconhecimento de mapas e ilustração de trajetos possuem compreensão mais difícil, todavia alcançável. Apesar de necessitarem maior atenção, as instruções entregues são suficientes para o idoso acompanhar a rota sugerida pela aplicação.

Um aplicativo que deseja ter o idoso como usuário deve utilizar uma linguagem simplificada e não economizar no emprego de ícones que o remetam ao objeto real. Os menus devem ser dispostos com opções diretas e triviais para que sejam intuitivas em sua seleção. As opções que necessitarem de configuração podem ser empregadas como alternativas que utilizem ícones, pois o sentimento de receio pode influenciar negativamente na experiência. 
De modo geral, o idoso apresenta engajamento com a aplicação com fator limitante no emprego da palavra configuração. Por outro lado, se mostram capazes de lidar com um grande conjunto de dados. O emprego de ícones durante a navegação torna a experiência mais agradável e com mínimas quebras no fluxo de busca por informações.

Este trabalho buscou identificar particularidades que devem ser levadas em consideração quando se pretende gerar aplicações que atendam ao público idoso. Embora seja mais natural, para os mais jovens, explorar os fluxos de navegação ofertadas pelo produto, o público mais velho não possui tal ímpeto.

A tecnologia, há alguns anos, era muito cara e pouco acessível, o que cativava o medo da interação, pois caso algum dano fosse causado o prejuízo era imenso. Assim, esse público foi crescendo e semeando e alimentando esse receio. Porém agora a realidade de alterou e explorar aplicações é o que auxilia no processo de aprendizagem digital.

Este trabalho foi executado pelo PET- COMPUTAÇÃO UFPel com o intuito de atender a um público muitas vezes esquecido quando se considera a tecnologia. Um grupo formado em uma universidade pública e que estuda inovação digital têm o compromisso de trazer públicos que necessitam de atenção para o protagonismo do estudo científico, assim como também auxiliá-los fortalecendo o pilar de extensão universitária.

\section{Agradecimentos}

Este trabalho foi realizado com o apoio do Ministério da Educação e do Fundo de Manutenção e Desenvolvimento da Educação Básica (FUNDEB). Agradecemos também o apoio da Universidade Federal de Pelotas.

\section{Referências}

A. Furtado, N. Almeida, A.B. Marques. 2018. Investigando a usabilidade de um aplicativo Internet Banking com usuários da terceira idade. IHC 2018.

A.H. Kronbauer, D. Machado, C.A.S. Santos. 2014. Uma plataforma para avaliar a experiência dos usuários com aplicativos para smartphones. WebMedia 2014.

Almeida, R. X. E. e Ferreira S. B. L. (2011). “Análise de Comportamento da Terceira Idade ao Efetuar uma Compra no Site Americanas.com”. X Simpósio de Fatores Humanos em Sistemas Computacionais, IHC e Latin American Conference on Human-Computer Interaction.

H. Väätäjä, T. Koponen, V. Roto. 2009. Developing practical tools for user experience evaluation - A case from mobile news journalism. European Conference on Cognitive Ergonomics 2009.

Marchi, A. C. B., Colussi, E. C., Zimmer, M., Trombetta, M. e Biduski, D. (2014). "Identificando Problemas de Usabilidade em um Aplicativo Móvel para Treino de Memória em Idosos". Interação Humano Computador. Foz do Iguaçu, PR.

Mol, A. M. e Ishitani, L. (2010). "Avaliação de interface de um aplicativo para uso em telefone celular e voltado para a terceira idade". Interação Humano Computador. Belo Horizonte, MG. 
Q. Chen, Y. Fan. 2012. Smartphone-based travel experience sampling and behavior intervantion. Transp. Research Board 91" Annual Meeting. 2012.

S.D.J. Barbosa, B.S. da Silva. Interação Humano-Computador. Rio de Janeiro. Elsevier, Série SBC, 2010.

Zajicek, M. Aspects of HCI research for older people. Universal Access in the Information Society 5, 3 (Oct. 2006), 279-286. 